\title{
Preparation and Characterisation of Oil Spill Dispersants Based on Polyglycerol Nonionic Surfactants
}

\author{
N.M.Khalil ${ }^{1}$, Ashgan I.Awad ${ }^{1}$, R.I.Abdallah ${ }^{1}$ and N.O.Shaker ${ }^{2}$

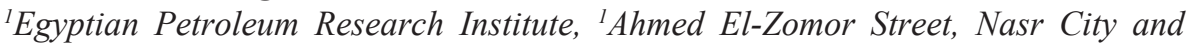 \\ ${ }^{2}$ Faculty of Science, Al-Azhar University, Cairo,Egypt.
}

\begin{abstract}
D ISPERSANTS, usually blended with several surfactants and a solvent, are used to enhance oil spill dispersion as small droplets in water column. Although there is growing acceptance of dispersants as a counter measure to marine oil spill around the world, the two major issues with the dispersants are their toxicity to marine life and dispersion effectiveness (DE) for crude oil. To develop more efficient and less toxic dispersants, three dispersants of hexaglycerol esters (hexaglycerol laurate, hexaglycerol myristate and hexaglycerol palmitate) non-ionic surfactants were prepared. Salinity at different temperatures of the three dispersants was investigated. They had high (DE) for studied crude oil. Emulsion stability was also examined and it was found that all the prepared surfactants were able to form stable emulsions and their stability was very high, extending for months.
\end{abstract}

Keywords: Polyglycerol, Fatty acids esters, Oil spill dispersants, Effectiveness, Emulsion stability.

\section{Introduction}

Surfactants are well known materials generally described as compounds bearing a hydrophilic and hydrophobic group per molecule. They are referred to as surface active agents that lower the surface tension and they may act as emulsifiers, detergents, dispersants and solubilising agent in the field of cosmetic, textile treatment and industrial field. Surfactant molecules will diffuse in water and concentrate at interface between air and water, in case where water is mixed with oil, or form aggregates in water such as micelles[1]. Today, new surfactants should be milder, safer and efficient with a minimal impact on the environment.

Environmental awareness and protection have led to the development of more environmentally benign surfactant. There is trend toward replacing petrochemicals by renewable materials [2]. Glycerol is one of the main by- products of oleo chemistry. In order to develop the possible uses of this by- product, researchers are focused on the synthesis of Polyglycerol and their non-ionic surfactants. Polyglycerols are the most often prepared by the polymerization of glycerol under alkaline conditions at elevated temperatures. Polyglycerol fatty acid esters are important nonionic surfactants with various applications in industries. Their amphiphilic character enables their use in the stabilisation of food emulsions[3] and various suspensions [4]. They can be used as a co-emulsifying agent in combination with mono acyl glycerols[5].

The majority of oil spills occur in coastal waters or in ports [6]. Therefore, contamination of the shoreline is likely at most spills, and thus the issues of oil recovery and shoreline cleanup must be addressed. Nearly all shoreline cleanup methods have some kind of environmental impact, so selection of a cleanup method is of great importance. The only really new techniques developed in the last few years involve chemical and biological treatment methods. The most commonly used surfactants are nonionic formulations. The motivations for using dispersants are to reduce the possibility of shoreline impact; reduce the impact on birds and mammals; and promote the biodegradation of oil in the water column. Effectiveness is the major issue with oil spill dispersants. Many factors

*Corresponding author e- mail: reneeibrahim@yahoo.co.uk

DOI : 10.21608/ejchem.2017.1445.1094

(C)2017 National Information and Documentation Center (NIDOC) 
influence dispersant effectiveness, including oil composition, which is the most important, sea energy, state of oil weathering, the type of dispersant used and the amount applied, temperature, and salinity of the water.

Dispersants blends show high dispersant effectiveness when compared with individuals, means synergistic agonistic interactions between dispersants [7]. Nevertheless, not all surfactant compositions are suitable for consisting dispersants to disperse spilled oil effectively, and many of the effective ones have the drawbacks of being toxic and/ or non-biodegradable[8].

Dispersants are used to break up an oil slick into numerous small droplets which become rapidly diluted into the water column and subsequently degraded by naturally occurring micro-organisms. Appropriate dispersants can be an effective response to an oil spill and can minimize or prevent damage to important sensitive resources [9]. Oil spill at sea was treated by spraying a detergent composite onto the oil and agitate the spilt oil and water so as to form an emulsion of the oil and water. The emulsion formed is diluted in water and consequently the spilt oil is dispersed as fine droplets thus reducing its effect on the marine environment and assisting its biodegradation[10].

The main objective of this work is to prepare a series of non-ionic surfactants based on polyglycerol fatty esters [lauric, myristic and palmitic acids]. These surfactants were tested for their surface tension reduction, emulsion stability and the effectiveness in dispersing crude oil. Some important factors that affect on dispersion effectiveness such as temperature, concentration of dispersants and salinity were investigated.

\section{Materials and Methods}

\section{Materials}

Anhydrous extra pure glycerol purchased from Merck, commercial fatty acids, lauric $(90 \%$ pure),myristic ( $90 \%$ pure), and palmitic (84\% pure) were obtained from Emery industries Inc.,all solvents are of pure grade. The tested crude oil was acquired from western desert

\section{Preparation of dispersants \\ Polymerization of glycerol}

Into a round flask,excess amount of dry glycerol and 2.5 moles of sodium hydroxide
$(\mathrm{NaOH})$ were added. The flask was equipped with a variable speedagitator and nitrogen sparge. The glycerol- sodium hydroxide mixture was agitated and heated to $220-260^{\circ} \mathrm{C}$ for 3 hours. The volatilized water from the reaction was trapped and measured.

The reaction was monitored by hydroxyl value and considered complete when a hydroxyl value of hexaglycerol was achieved. Then the reaction mixture was cooled to avoid further polymerization of glycerol.

\section{Esterification}

Into a round bottom flask 2.74 moles of fatty acid and 2.11 moles of polyglycerol prepared from previous step were added, the flask was fitted with a mechanical stirrer, temperature control and nitrogen sparge. The mixture was heated to $230^{\circ} \mathrm{C}$ for 3-4 hours until it was clear and had an acid value below 2 . Sodium hydroxide remaining from the polyglycerol forming process was neutralized by adding phosphoric acid aqueous solution $(85 \%$ phosphoric acid and $15 \%$ water) at $230^{\circ} \mathrm{C}$. The mixture was stirred for another 15 minute and then cooled.

\section{Characterization of dispersants \\ Emulsifying ability}

Emulsifying power of the aqueous solutions of the three surfactants was determined for water/ liquid paraffin system. Aqueous solutions of the surfactants at different concentrations were prepared, $20 \mathrm{ml}$ aqueous solution of the surfactant was taken in $100 \mathrm{ml}$ stopped graduated measuring cylinder and $20 \mathrm{ml}$ of paraffin was poured into it from the side of the wall. The cylinder was kept at room temperature $\left(25^{\circ} \mathrm{c}\right)$. After sufficient time the cylinder containing solution was turned upside down for 30 times at the rate of 1 turn per 2 seconds. The time of separation of aqueous phase for $20 \mathrm{ml}$ was noted [11].

\section{Surface tension measurements}

The surface tension of different concentrations of surfactant aqueous solutions was measured using Du NouyTensiometer equipped with platinum-iridium ring at $25^{\circ} \mathrm{C}$. The tensiometer was calibrated using doubly distilled water. The average value of three measurements of the surface tension data was used.

Dispersion efficiency [12]

A definite amount of sea water sample 
$(250 \mathrm{ml})$ was transferred to a separating funnel and maintained at required temperature, and then $(5 \mathrm{~cm})$ of used crude oil was added to the water surface and left for one minute. Then a known amount of dispersant was added. After a time of 2.5 minutes from the addition of oil, the oil was shacked for two minutes, then $50 \mathrm{~cm}$ of the oily waterwas drown in a $50 \mathrm{~cm}$ measuring cylinder in a time not exceeding 10 seconds. Then, the oily water was transferred from the measuring cylinder to separating funnel.

The measuring cylinder was washed twice with $10 \mathrm{ml}$ of chloroform where washing was added to the separating funnel, and shacked for one minute. The phases were allowed to separate completely and run off the chloroform layer through a Whatman filter paper No. 1 containing anhydrous sodium sulfate. The chloroform extract was repeated twice more using $20 \mathrm{ml}$ chloroform. The dried extracts and washings were combined; in $100 \mathrm{ml}$ volumetric flask to the mark, stoppered and mixed well. Calibration, of the used crude oil was carried out at different concentrations $(0.2$, $0.5,0.7$ and $0.9 \mathrm{~g}$ ) in chloroform. The absorbance of each solution was measured at $580 \mathrm{~nm}$ and the calibration curve (absorbance against concentration was drawn.

The absorption of the chloroform extract was measured against a chloroform blank at 580nm in glass cells of $5 \mathrm{~mm}$ path length. Using the calibration curve the weight of the oil; contained in the $50 \mathrm{ml}$ oily water sample was calculated.

The efficiency index E, was calculated from the following equation.

Weight of oil in $50 \mathrm{ml}$ sample of oily water x 500

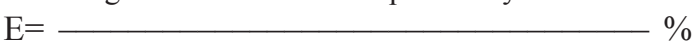

Total weight of added oil to $250 \mathrm{ml}$

Physicochemical characteristics of the tested crude oil

The general physicochemical characteristics of the crude oil, such as density (ASTM D-12981), kinematic viscosity (ASTM D-445), pour point (ASTM D-97), wax content (UOP-64) and flash point (ASTM D- 93) were determined according to standard tests methods ASTM, and UOP $[13,14]$ standard methods (Table 5).

Separation of undispersed crude oil to its hydrocarbon types

Deasphalting for crude oil sample was carried out before and after treatment with different surfactants at different temperatures, using the standard test method IP 143 [15] method.

The obtained maltene was separated into its components saturate, aromatic and resin, using liquid column chromatography [16]. Identification of different hydrocarbon components was achieved according to refractive index(R.I) of each one as shown in Table 1.

TABLE 1. Refractive index of hydrocarbons.

\begin{tabular}{|c|c|}
\hline Hydrocarbons & R.I at $20^{\circ} \mathrm{C}$ \\
\hline Saturates & $<1.48$ \\
\hline Mono aromatics & $1.48-1.53$ \\
\hline Diaromatic s & $1.53-1.59$ \\
\hline Polyaromatics & $>1.59$ \\
\hline Resins & Dark \\
\hline
\end{tabular}

Methods

\section{Tensiometer}

The surface tension of the prepared dispersants was measured using $\mathrm{Du}$ NouyTensiometer equipped with platinum-iridium ring.

Gas chromatography (GC)

Saturated hydrocarbons separated before and after treatment with surfactant, were chromatographically analyzed according to the standard test method IP 318 [15]. The component separation was completed on HP-1 capillary column (100\% methyl silicone siloxane, $30 \mathrm{~m}$ length, $0.35 \mathrm{~mm}$ internal diameter and $0.25 \mathrm{~mm}$ thickness film), using Agilent 6890 plus Gas Chromatograph provided with flame ionization detector [17].

\section{High performance liquid chromatography (HPLC)}

Separated aromatics from the studied crude sample and the crude oil remained after treatment by surfactants at different temperatures have been studied by HPLC. Sample was analyzed using HPLC instrument model 600E, equipped with dual UV absorbance detector Waters 2487and auto sampler Waters 717 plus, attached to a computerized system with Millennium 3.2 software [18].

\section{Results and Discussion}

The polymerization of glycerol involves the

Egypt.J.Chem. 60, No.5 (2017) 
$\alpha$-hydroxyl groups of two glycerol molecules to form an ether linkage with release of a water molecule (Fig.1). Polyglycerols were prepared by the polymerization of glycerol under alkaline conditions $(2.5$ mole $\%$ of $\mathrm{NaOH})$ at $260^{\circ} \mathrm{C}$ and under nitrogen atmosphere for 3 hours.

The two $\alpha$-hydroxyl groups remaining on the diglycerol molecule formed are available for

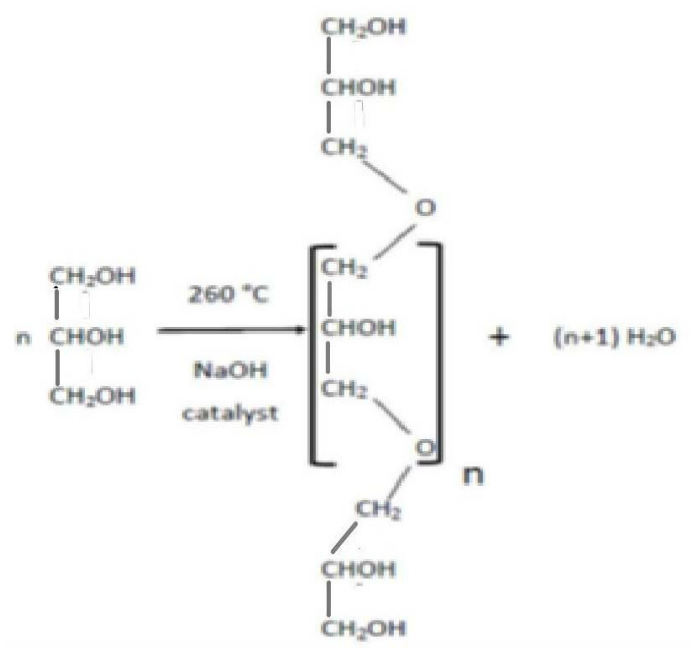

reaction with other molecules of glycerol or other polymerized molecules. The reaction produces polymers which are almost entirely linear [19]. Care must be taken during the polymerization reaction to exclude air from the system. Traces of oxygen lead to the formation of acrolein as well as a dark product which is not easily bleached.

The reaction rate was followed by determination of hydroxyl value. The hydroxyl value is the best indicator of the amount of polymerization which has occurred as shown in Table 2. When the desired hydroxyl value of the polymer was reached, the reaction was terminated by cooling. On the other hand, the progressive increase in the viscosity is also an evidence of polymerization. The second step esterification reaction was done after cooling the polymer to as low as $160^{\circ} \mathrm{C}$. Lower temperatures also guarantee that further polymerization of glycerol will be avoided. Since the esterification can be done either at alkaline or neutral conditions, no additional catalyst was needed.

Fig.1. Polymerization of glycerol.

TABLE 2. Physicochemical characterization of Glycerol heated at $260^{\circ} \mathrm{C}$ for different periods of time.

\begin{tabular}{|c|c|c|c|c|c|c|c|c|c|c|}
\hline \multirow{2}{*}{$\begin{array}{c}\text { Time of } \\
\text { Polymerization } \\
\text { (min) }\end{array}$} & \multirow{2}{*}{ Polyol } & \multirow{2}{*}{$\begin{array}{c}\text { Yield } \\
\%\end{array}$} & \multirow{2}{*}{$\begin{array}{r}\mathrm{OH} \\
\text { Calc. }\end{array}$} & \multirow{2}{*}{$\begin{array}{l}\text { Value } \\
\text { Found }\end{array}$} & \multicolumn{2}{|c|}{ OH \% } & \multicolumn{2}{|c|}{$\begin{array}{l}\text { No of OH } \\
\text { groups }\end{array}$} & \multirow{2}{*}{$\begin{array}{l}\text { Specific } \\
\text { gravity }\end{array}$} & \multirow{2}{*}{$\begin{array}{l}\text { Viscosity } \\
\left(\mathbf{C P}, \mathbf{6 5}^{0}\right. \\
\mathrm{C})\end{array}$} \\
\hline & & & & & Calc. & Found & Calc. & Found & & \\
\hline 0 & Glycerol & 90 & 1829 & 1750 & 55 & 50 & 3 & 2.7 & 1,251 & 760 \\
\hline 90 & Diglycerol & 93 & 1351 & 1340 & 41 & 39 & 4 & 3.7 & 1.260 & 870 \\
\hline 180 & Tetraglycerol & 91 & 1071 & 1028 & 31 & 29 & 6 & 5.6 & 1.273 & 1130 \\
\hline 260 & Hexaglycerol & 92 & 971 & 934 & 30 & 28 & 8 & 7.7 & 1.285 & 1950 \\
\hline
\end{tabular}

It is worth noticing that the sodium hydroxide that was added as a catalyst in the polymerization step of glycerol has an additional important role in the esterification process. It transforms part of the fatty acid to its sodium salt which helps to solubilize the polyglycerol in the product. The fatty acids [lauric, myristic and palmitic acids] were added to the hexaglycerol, the reaction proceeded smoothly at elevated temperature $\left(230^{\circ} \mathrm{C}\right)$ and system was agitated well. The only byproduct of the reaction is water, which is immediately trapped. The reaction was carried out under inert atmosphere to obtain good color, flavor and odor characteristics. The reaction was considered complete when the acid value was less than two. And at the end of the esterification, the mixture was cooled to room temperature. The unreacted polyglycerols did not dissolve at room temperature in the polyglycerol esters, thus any excess of unreacted polyglycerol can be separated from the product by simple decantation. The rate of reaction was determined by calculating the acid value, the saponification value and the ester value of the products.

The solubility of esters in water, ethanol and isopropanol was determined. The data in Table 3 give an indication of the hydrophilic 
(lipophilic) nature of the esters. The increasing molecular weight of the aliphatic chain (from laurate to palmitate) tended to lower solubility. All esters were found to be completely miscible in $95 \%$ ethanol and were soluble for laureate and myristate and insoluble for palmitate in water and isopropanol at $1 \%$ level, but $10 \%$ level they were all dispersible. In general, the solubility studies indicated that as expected, the hexaglycerol laurate was the most hydrophilic whereas the hexaglycerol palmitate was the least hydrophilic.

TABLE 3. Solubility of hexaglycerol esters.

\begin{tabular}{|llc|}
\hline Hexaglycerol Ester & \multicolumn{2}{c|}{ Hexaglycerol ester, \% added } \\
Water & $\mathbf{1 \%}$ & $\mathbf{1 0 \%}$ \\
Hexaglycerol Laurate & & \\
Hexaglycerol myristate & $\mathrm{S}$ & $\mathrm{D}$ \\
Hexaglycerol palmitate & $\mathrm{S}$ & $\mathrm{D}$ \\
Ethanol & $\mathrm{I}$ & $\mathrm{D}$ \\
$\underline{\text { Isopropanol }}$ & $\mathrm{All}$ \\
Hexaglycerol Laurate & $\mathrm{S}$ & $\mathrm{D}$ \\
Hexaglycerol myristate & $\mathrm{S}$ & $\mathrm{D}$ \\
Hexaglycerol palmitate & $\mathrm{I}$ & $\mathrm{I}$ \\
\hline
\end{tabular}

$\mathrm{S}=$ Soluble $; \mathrm{D}=$ Dispersible $; \mathrm{I}=$ Insoluble

The surface tension at the critical micelle concentration (cmc) was calculated. Table 4 indicates that values for hexaglycerol laurate, myristate and palmitate are 27, 30.5 and 32.3 $\mathrm{mN} / \mathrm{m}$, respectively.

Since the long chain esters of several polyglycerols have been found to be very useful as dispersants or emulsifiers in diverse applications [9], a simple test for emulsification was carried out. Emulsifying power of the aqueous solutions of the three surfactants was determined for water /liquid paraffin system. Stable emulsion was formed using surfactant solution to oil in a ratio of $1: 1(\mathrm{~V}: \mathrm{V})$. A creamy emulsion of oil in water was observed.
The more is the time required for clearing the two layers; the high is the emulsifying power of the surfactant. On storage, it was observed that the creamy stability gradually decreases. This may be result of droplet break and not droplet formation. The emulsifying power of the surfactants at different concentrations is shown in Table 4 [20].

It is clear that the emulsifying power of the hexaglycerol laurate is the highest, and decreases when the chain length of the fatty acid increases, showing the lowest values with hexaglycerol palmitate. It is also observed that increasing the concentration of the surfactants increase the emulsifying power as clear in Table 4.

TABLE 4. Surface tension at cmc and emulsifying ability of hexaglycerol esters at $25^{\circ} \mathrm{C}$.

\begin{tabular}{|c|c|c|c|c|}
\hline \multirow[t]{2}{*}{ Hexaglycerol Esters } & \multirow[t]{2}{*}{$\begin{array}{l}\text { Surface tension at cmc } \\
\qquad(\mathrm{mN} / \mathrm{m})\end{array}$} & \multicolumn{3}{|c|}{$\begin{array}{l}\text { Emulsifying ability( day) } \\
\text { Conc }(\mathrm{g} / 100 \mathrm{ml})\end{array}$} \\
\hline & & 0.1 & 0.2 & 0.4 \\
\hline Laurate & 27.0 & 24 & 25 & 30 \\
\hline myristate & 30.5 & 21 & 23 & 26 \\
\hline Palmitate & 32.3 & 13 & 18 & 20 \\
\hline
\end{tabular}


The physicochemical characterization of the studied crude oil was carried out; results were illustrated in Table 5. The results show that the studied crude oil had API 21.9, kinematic viscosity $394.55,140.15$ and 60.86 at the studied temperatures $10^{\circ} \mathrm{C}, 20^{\circ} \mathrm{C}$ and $30^{\circ} \mathrm{C}$, respectively. It was concluded that the studied crude oil is considered as middle crude oil with low pour point and low wax content [21].

TABLE 5. Physicochemical properties of crude oil.

\begin{tabular}{|lcc|}
\hline Properties & Value \\
Density g/ml, @ $15.56^{\circ} \mathrm{C}$ & 0.9011 \\
Specific gravity & & 0.920 \\
API gravity & & 21.9 \\
& & \\
Kinematic Viscosity, cSt $@ 10^{\circ} \mathrm{C}$ & 394.55 \\
& $@ 20^{\circ} \mathrm{C}$ & 140.15 \\
& @ $30^{\circ} \mathrm{C}$ & 60.86 \\
Pour point, ${ }^{\circ} \mathrm{C}$ & & 9 \\
Wax content, wt \% & & 2.41 \\
Flash point, ${ }^{\circ} \mathrm{C}$ & 35 \\
\hline
\end{tabular}

The dispersion efficiency of the three prepared dispersants, hexaglycerol laurate, myristate and palmitate for crude oil was studied at different temperatures $\left(10^{\circ} \mathrm{C}, 20^{\circ} \mathrm{C}\right.$ and $\left.30^{\circ} \mathrm{C}\right)$, results are illustrated in Table 6 . From the results obtained it is clear that the dispersion efficiency depends on the property and the composition of the dispersed oil, the applied temperature and the surfactant used. It was found that at low temperature $\left(10^{\circ} \mathrm{C}\right)$ where the viscosity is high $(394.55 \mathrm{cSt}$ ) and pour point is $9^{\circ} \mathrm{C}$, the dispersion efficiency is low for all surfactant due to the low tendency of crude oil to be dispersed [22]. Increasing the concentration of dispersant (increasing the dispersant oil ratio) the dispersion efficiency increases due to decrease of oil water interfacial tension which facilitates the formation of large number of small droplets that can be entered into the water column $[21,22]$.

It was also noticed that increasing temperature to $20^{\circ} \mathrm{C}$ and $30^{\circ} \mathrm{C}$ decreased the viscosity which improved the dispersion efficiency especially for hexaglyceryl laurate ester due to its shortest chain length and highest emulsifying powercompared with hexaglycerol myristate and hexaglycerol palmitate which facilitate the dispersion of crude oil. It was concluded [22] that dispersion efficiency increased with increasing both temperature and concentration of the dispersants (Table 6).

From the parameters that detect the rate of dispersion are the changes in percentage of components and hydrocarbon type of the undispersed part as result of treatment with different dispersants. Thus the hydrocarbon components of higher obtained efficiency at $20^{\circ} \mathrm{C}$ and $30^{\circ} \mathrm{C}$ for hexaglycerol laurate ester were studied.

The recovered undispersed crude oil samples for the untreated and treated crude oil at $20^{\circ} \mathrm{C}$ and $30^{\circ} \mathrm{C}$ were separated into their components by deasphalting and deresining techniques. The results obtained in Tables $6 \& 7$ indicate that by increasing efficiency at higher temperature the higher the amount of asphaltenes, resins and aromatics left in the undispersed part of the oil $[23,24]$.

The hydrocarbons type analysis may be used as a marker of the degree of dispersion which is in agreement with the lower percentage of saturates at $20^{\circ} \mathrm{C}$ and high aromatic content which indicate a high degree of dispersion, since the aromatic hydrocarbons are more resistant to dispersion. The high asphaltenes content may, also indicate a high degradation degree, because during dispersion process condensation of molecules occur and additional high boiling materials were formed by oxidative polymerization resulting formation of asphaltenes and resins.

TABLE 6. Efficiency of different dispersants at different temperatures.

\begin{tabular}{|c|c|c|c|c|c|c|c|c|c|}
\hline \multirow{2}{*}{ Conc.\% } & \multicolumn{3}{|c|}{ Laurate ester } & \multicolumn{3}{|c|}{ Myristate ester } & \multicolumn{3}{|c|}{ Palmitate ester } \\
\hline & 0.1 & 0.2 & 0.4 & 0.1 & 0.2 & 0.4 & 0.1 & 0.2 & 0.4 \\
\hline 10 & 8.24 & 11.39 & 15.60 & 7.12 & 9.14 & 14.50 & 6.35 & 7.40 & 13.7 \\
\hline 20 & 25.61 & 30.58 & 43.23 & 21.70 & 23.85 & 27.50 & 17.8 & 22.03 & 24.95 \\
\hline 30 & 29.01 & 43.02 & 59.64 & 25.79 & 30.1 & 39.5 & 22.03 & 26.64 & 32.34 \\
\hline
\end{tabular}

Egypt.J.Chem. 60, No.5 (2017) 
TABLE 7. Hydrocarbon composition of undispersed crude oil.

\begin{tabular}{|c|c|c|c|c|c|}
\hline & & & & Maltene & \\
\hline Sample & wt $\%$ & wt \% & $\begin{array}{c}\text { Saturate } \\
\text { wt } \%\end{array}$ & $\begin{array}{c}\text { Aromatic } \\
\text { wt } \%\end{array}$ & $\begin{array}{l}\text { Resin } \\
\text { wt \% }\end{array}$ \\
\hline Control crude oil & 1.82 & 98.38 & 62.28 & 23.51 & 14.21 \\
\hline Sample at $20^{\circ} \mathrm{C}$. & 11.36 & 88.64 & 46.35 & 36.35 & 16.21 \\
\hline Sample at $30^{\circ} \mathrm{C}$. & 12.74 & 87.30 & 38.36 & 44.63 & 17.01 \\
\hline
\end{tabular}

The gas chromatography of saturates separated from the studied crude oil and the undispersed crude at $20^{\circ} \mathrm{C}$ and $30^{\circ} \mathrm{C}$ are represented in Fig. 2. The chromatogram shows a gradual increase in n- paraffinic hydrocarbon percentage by increase in carbon number from $\mathrm{C}_{12}$ up to $\mathrm{C}_{20}$ followed by continuous decrease of carbon number up to $\mathrm{C}_{46}$. Hexaglycerollaurate ester at $20^{\circ} \mathrm{C}$ show high decrease in carbon number of both normal and iso alkanes up to $\mathrm{C}_{15}$ due to their dispersion, while no remarkable change in the percentage of higher molecular weight paraffin up to $\mathrm{C}_{41}$, but there is complete dispersion of $\mathrm{C}_{42}$ to $\mathrm{C}_{46}$. The increase of efficiency by increasing temperature was clear from high decrease in all normal alkanes with complete dispersion of $\mathrm{C}_{39}$ to $\mathrm{C}_{46}$ [24].

The normal alkanes to isoprenoid ratio is normally greater than the unity, and decrease as dispersion proceeds, since normal alkanes are usually degraded more rapidly than isoprenoid alkanes. The high dispersability of normal alkanes makes its molecules more available to biodegrading by microorganisms [25].

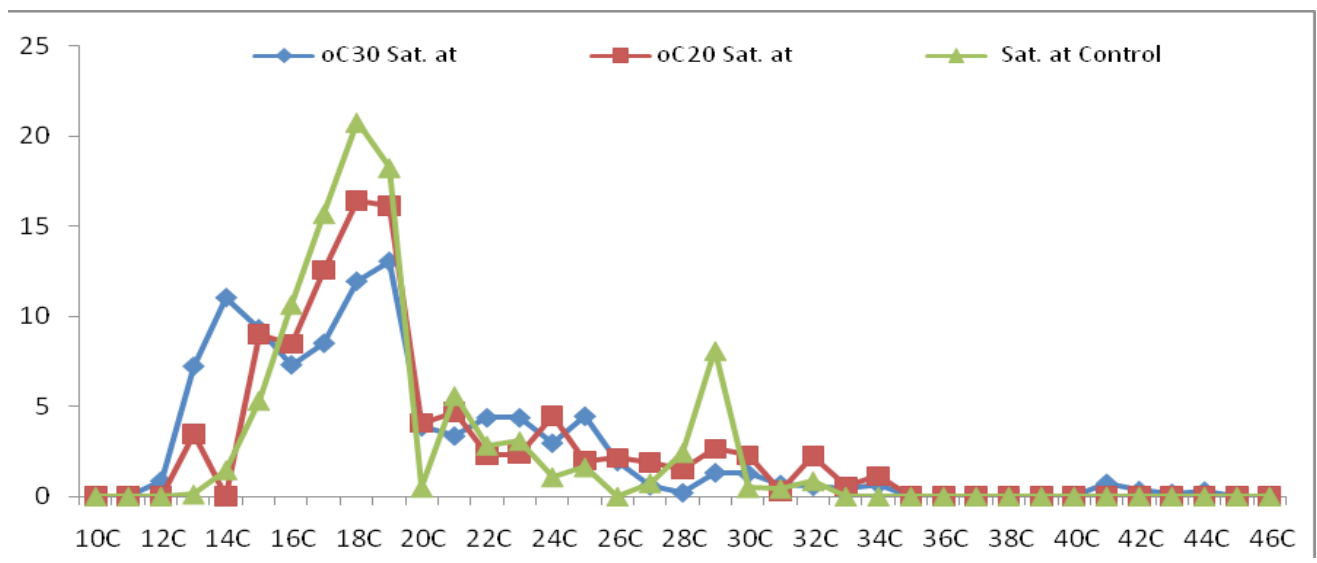

Fig. 2. Distribution of saturates for control crude oil and saturates separated at $20^{\circ} \mathrm{C}$, saturates separated at $30^{\circ} \mathbf{C}$.

Polycyclic aromatic hydrocarbons (PAHs) are potent environmental pollutants that comprise fused aromatic rings. The presence of PAHs in the environment is related to human activities in petroleum exploration and refining operations [2426]. Incomplete combustion at high temperature appears to be one of the major anthropogenic sources of environmental PAHs contamination. The importance of PAHs as pollutants is due to their hydrophobic and recalcitrant nature. PAHs are ubiquitous contaminants in the environment with potential mutagenicity and carcinogenicity. Low molecular weight PAHs are high toxic and most of the high molecular weight PAHs are mutagenic and carcinogenic [24,25].
From HPLC study of the undispersed aromatics fraction, it is clear that using hexaglycerol laurate at $20^{\circ} \mathrm{C}$ and $30^{\circ} \mathrm{C}$ two rings fused (naphthalene) are formed. And a marked decrease in the concentration of three rings aromatics at $30^{\circ} \mathrm{C}$ $(5.07 \%)$ and six rings at $20^{\circ} \mathrm{C}$ and $30^{\circ} \mathrm{C}(0.22$ and $0.09 \%$ ) were observed respectively $[26,27]$.

Surfactants have different solubility in water. Apart from the consideration of environmental benefits of dispersing oil in fresh or brackish water, there is an issue as to whether or not dispersants will work or not. The major available dispersants have been formulated for use in normal marine salinity of $30 \%$ or higher and it is well known 
that effectiveness decrease at lower salinity as the thus less available to interact with the oil $[28,29]$. surfactant become more soluble in low saline water

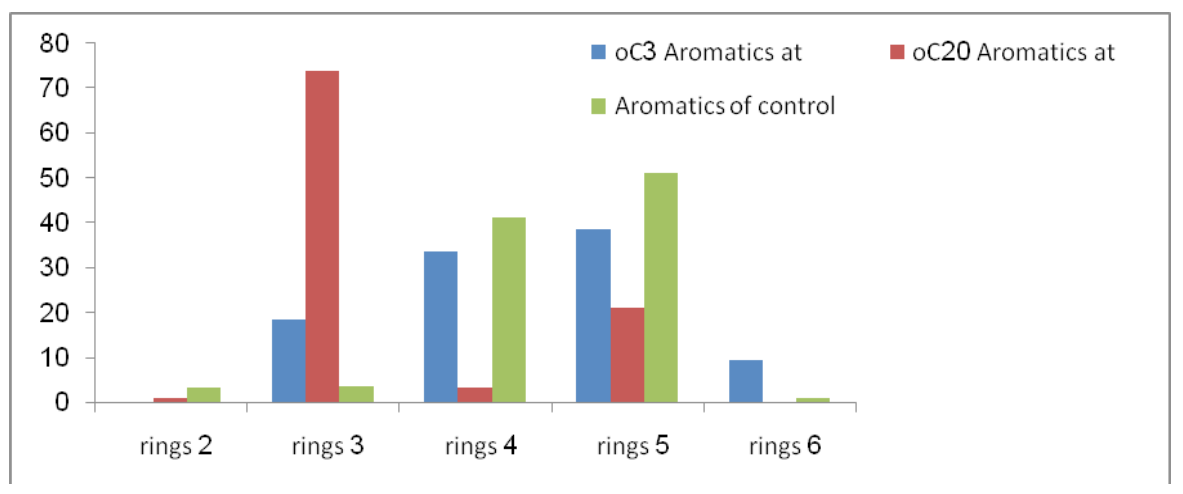

Fig. 3. Polyaromatics distribution of control crude oil and polyaromatics separated at $20^{\circ} \mathrm{C}$ and polyaromatics separated at $30^{\circ} \mathrm{C}$.

The dispersion efficiency of dispersants at different temperature, concentration and salinity, using fresh water $0.02 \% 0$, Mediterranean Sea water $30.3 \% 0$ and Red Sea water $40.2 \%$ 0 , has been studied using hexaglycerol laurate ester as a dispersant which showed the highest effectiveness at salinity $30.3 \% 0$ (Mediterranean Sea) at $20^{\circ} \mathrm{C}$ and $30^{\circ} \mathrm{C}$. It was also noticed that highest efficiency at high temperature and also high concentration as shown in Table 8.

TABLE 8. Dispersion efficiency of hexaglycerol laurate at different salinity.

\begin{tabular}{|c|c|c|c|c|c|c|c|c|c|}
\hline \multirow{3}{*}{${ }_{\text {Conc. } \%}^{\text {Temperature }}$} & \multicolumn{9}{|c|}{ Dispersion efficiency } \\
\hline & \multicolumn{3}{|c|}{ Fresh water } & \multicolumn{3}{|c|}{ Mediterranean Sea } & \multicolumn{3}{|c|}{ Red Sea } \\
\hline & 0.1 & 0.2 & 0.4 & 0.1 & 0.2 & 0.4 & 0.1 & 0.2 & 0.4 \\
\hline 20 & 10.25 & 19.2 & 27.76 & 25.61 & 30.58 & 43.23 & 9.79 & 17.54 & 20.00 \\
\hline 30 & 19.87 & 25.42 & 30.27 & 29.01 & 43.02 & 59.64 & 14.97 & 22.15 & 48.21 \\
\hline
\end{tabular}

\section{Conclusion}

- The prepared hexaglycerol esters of varying chain length and varying polymer length strongly indicates the broad scale range of hydrophilic to lipophilic products which should have potential utilization in the clinical, dietary and oil spill applications.

- From the solubility studies of the three prepared dispersants, hexaglycerol laurate, hexaglycerol mystirate and hexaglycerol palmitate it was observed that hexaglycerol laurate was the most hydrophilic one while the later) hexaglycerol palmitate (is the least

- Moreover, the emulsifying power of hexaglycerol laurate is the highest one and decreases with increasing the chain length of fatty acid, showing the lowest values with hexaglycerol palmitate.
- Dispersantshad high dispersion effectiveness by increasing temperature, concentration of dispersant, decrease the chain length of fatty acid and at moderate salinity.

- From hydrocarbons types analysis of undispersed crude oil by using hexaglycerol laurate, high asphalteneand aromatic contents were obtained which confirm its high dispersion effectiveness.

- G.C study of separated saturate fraction shows high dispersability of n-alkanes thus more availability to biodegradation by microorganisms.

- HPLC study of PAHs shows high decrease in six member ring causing a high carcinogenic effect. 


\section{References}

1. Adewug,A., Gopfert,A., Wolf,T., Central European Journal of Chemistry, 11 (8),1368-1380 (2013).

2. Folmer, B.M., Holmeberg, K., Klingoskog ,E.G., and Bergstrom, K., Journal of Surfactant and Detergent, 4, 175-183 (2001).

3. Hember,W., J. Am. Oil. Chem. Soc., 58,114 (1981).

4. Babayan, V.K., Mc in tyre, R.T., J. Am. Oil. Chem. Soc., 48, 307 (1971).

5. Garti, N., and Ascrin, A., Bakers Digest., 67, 19 (1981).

6. .Haapkylal, F. and Ramade and B. Salvat, Life and Environment, 57 (1-2), 91-107 ( 2007).

7. Al-Sabagh, A. M.;, El-Hamouly, . S. H.; Atta, A. M.; El-Din M. R. N and Gabr M. M., Journal of Dispersion Science and Technology, 28(5) , 661-670 (2007).

8. Venttikos, N.p., Vergetis E., Psaraftis, N. and Triantafylou ., J. of Hazardous Materials, 107 (12), 51-58 (2005).

9. Srinivasan, R., Lu, Q., Sorial, G. A., Venosa A. D. and Mullin, J. Environmental Engineering Science, 24(9) و pp. 1307-1320 (2007)

10. Chapman H, Purnell K, Law RJ, Kirby MF..Mar Pollut Bull. 2007 Jul; 54 (7),827-38. May 17(2007).

11. Xu R.F., Xu H.J., Xu H.,Chen L., Appl. Chem. Ind. 41, 317-320 (2012).

12. Asmaa A.A. Meky; Thesis submitted for M. Sc. Studied, Helwan Univ., Cairo, Egypt (2014).

13. . ASTM ; "Annual Book Of Standards Petroleum Products and Lubricants". Section 5, American Society for Testing and Material, Philadelphia, U.S.A., 05. 01 (05. 03), (2005).

14. UOP; Laboratory Tests Methods for Petroleum and its Products." University Oil Products Co., Chocago, U.S.A. (1985).

15. IP; "Standards for Analysis and Testing of Petroleum and Related Products." Institute of
Petroleum, London (2005).

16. Mulabagal, V., Yin, F., John, G. F., Hayworth, J. S., \& Clement, T.P.from Alabama Marine Pollution Bulletin, 70 (1-2), (2013).

19. Babayan, V. K., Kaufman, T. G., Lehman, and Tkaczuk, R J. Journal of Society of Cometic Chemists, 15, 473 (1964).

20. Al-Sabagh , A. M, Morsi , R. E., Elsabee, M. Z. Naguib, H. F., and Moustafa ,Y. M., Journal of Dispersion Science and Technology, 33, 16611666 (2012).

21. Mukherjee, B. and Wrenn, B. A., Environmental Engineering Science, 28, (4), 263-273 (2011).

22. Dandan Song, Shengkang Liang, Qianqian Zhang, Jiangtao Wang, Limei Yan., Journal of Environmental Protection, , 4, 16-22 (2013).

23. Omayma E. Ahmed;Sawsan A. Mahmoud and Abd El Rahman M. Mousa, International Journal of Environment ISSN: 2077-4508, 04 | Issue : 01 , Jan-Mar. Pages: 70-86 (2015).

24. Nagla, M.,. Thesis submitted for Ph D. Studied on Pollutants Contaminating Red Sea Marine Environmental with Special Emphasis to Aromatic Hydrocarbons Al-Azhar University, Girls Branch, (2007).

25. .Hussein I. Abdel-Shafy , Mona S.M. Mansour, Egyptian Journal of Petroleum, 25, 107-123. (2016)

26. Essam, N., Y. H.; Lee, Z. Zuriati ;S. Salmijah; Journal of Chemistry, ID 975781: 10 (2013).

27. .Mostafa M. E.;Nazik, A. F.; Enas, A. E.;Omayma, E. A. and Eman, M. K.;Egypt. J. Anal. Chem. 23, 54-73 (2014).

28. Chuvilin E. M. and Miklyaeva E. S.; Cold Regions Science and Technology, 37(2), 89-95 (2003).

29. Chandrasekar , S.;Sorial G. A.and Weaver, J. W., ICES Journal of Marine Science, 63(80), 14181430 (2006)

(Received 7/ 8/2017; accepted 19/9/2017) 


\section{إعداد وتوصيف المشتتات ذات النشاط السطحي غير الأيونية استنادا إلي عليد الجليسيرول لعلاج الأنسكاب النفطي

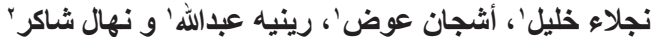

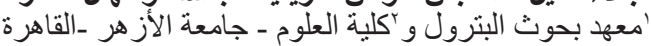

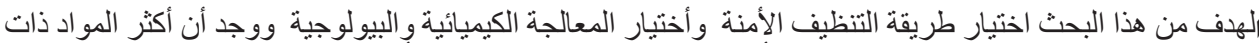

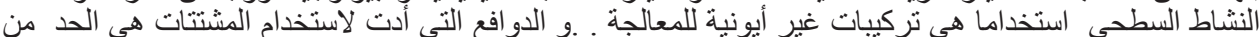

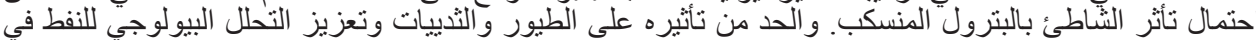
عمود المياه و القضيةالرئيسية مع مشتتات هي كفاءتة في علاج الزيره الزيت المنسكب.

لقد تم إعداد ثلاثة مشتتات من سداسية الاسترات (هيكساجليسيرول لوريت، هيكساجليسيرول ميريستات و

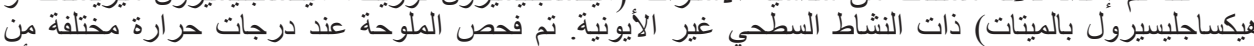

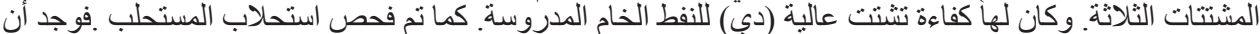

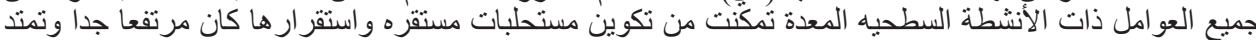

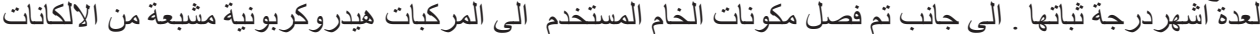

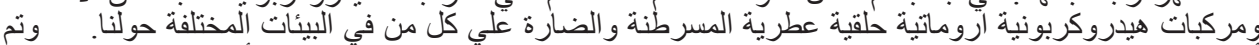

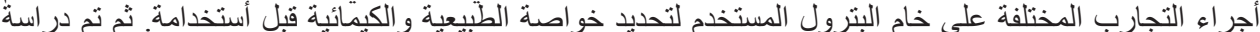

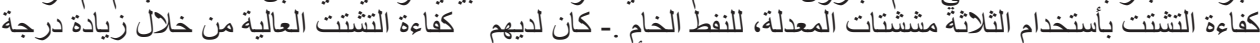

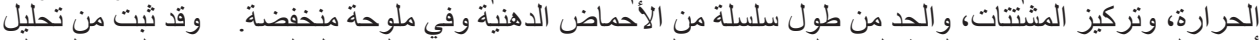

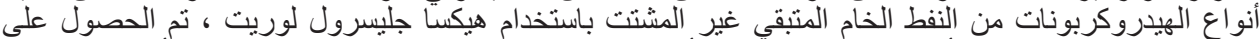

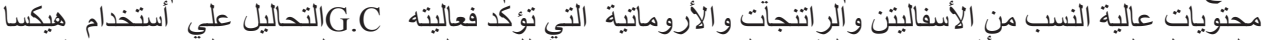

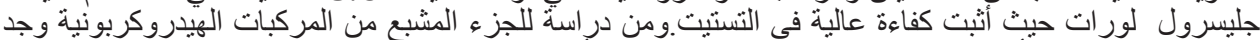

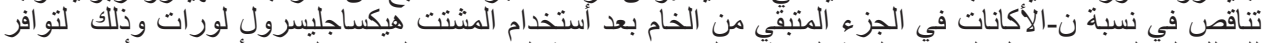

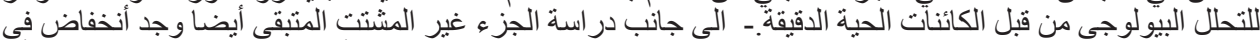

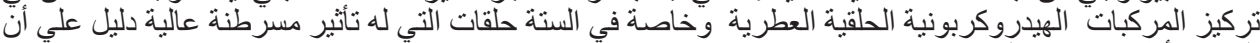
المشتت أظهر كفاءة عالية. 